\title{
Seasonal Transmission of Leishmania (Leishmania) mexicana in the State of Campeche, Yucatan Peninsula, Mexico
}

\author{
Fernando J Andrade-Narvaez ${ }^{+}$, Silvia B Canto Lara, Nicole R Van Wynsberghe, \\ Eduardo A Rebollar-Tellez, Alberto Vargas-Gonzalez, Nelly E Albertos-Alpuche
}

Universidad Autónoma de Yucatán, Centro de Investigaciones Regionales “Dr. Hideyo Noguchi”, Laboratorio de Inmunología, Avenida Itzáes No. 490x59, Código Postal 97000, Mérida, Yucatán, México

In the Yucatan Peninsula, Mexico, localized cutaneous leishmaniasis (LCL) caused by Leishmania (Leishmania) mexicana is a typical wild zoonosis restricted to the forest, and humans are only accidentally involved. The transmission of L. (L.) mexicana has been related to the patient's occupation: "chicleros" (gum collectors) and agricultural workers. The objective of this study was to document L. (L.) mexicana seasonally of transmission in endemic areas of LCL in the state of Campeche, Yucatan Peninsula, Mexico. The timing of incidence of LCL in humans during 19931994, as well as the rate and time of infection in rodents and sand flies between February 1993 and March 1995 were analyzed. Rodents and sand flies were found infected between November and March, when men carried out their field activities and are exposed. Based on results analyzed, it is concluded that L. (L.) mexicana in the endemic area of LCL in the state of Campeche, Yucatan Peninsula, Mexico, presents a seasonal transmission restricted to the months of November to March. The knowledge of the timing of the transmission cycle in an endemic area of leishmaniasis is very important because intervention measures on the high-risk focus and population might be restricted.

Key words: Leishmania (Leishmania) mexicana - seasonal transmission - Mexico

Leishmaniases are mostly zoonotic diseases. The outset of the disease in patients, the relative abundance of vector and reservoir species, and their rate and time of infection are the major components for the study of the "epidemiological triangle" (Lainson 1988) in the transmission of the disease. When all the eco-epidemiological elements are present, an outbreak of the disease occurs. The disease might follow an irregular pattern of high epidemic bursts or regular biological cycles. These transmission cycles might range over several years or be seasonal.

Outside Mexico, very few observations of time variation in number of patients with leishmaniases have been reported (e.g. Gentile et al. 1981, Lindtjorn 1984, Coronel et al. 1987). Even more rarely is the publication of the timing of appearance of infected wild hosts, potential reservoir of Leishmania spp. (Bettini et al. 1980, Kerr et al. 1995).

The seasonal abundance of sand flies have been more often studied (e.g. Strangways-Dixon \& Lainson 1966, Chaniotis et al. 1971, Ready et al. 1984, Travi et al. 1988, Gomez et al. 1990).

In the Yucatan Peninsula, LCL is a typical wild zoonosis restricted to the forests, and human is only accidentally involved (Lainson \& Strangways-Dixon 1963,

Financial support: UNDP/World Bank//WHO Special Programme for Tropical Diseases Research (TDR) RCS/TDR/ WHO ID 900248

${ }^{+}$Corresponding author. Fax: (52-999) 923-6120. E-mail: anarvaez@tunku.uady.mx

Received 3 July 2003

Accepted 20 October 2003
1964, Chablé-Santos et al. 1995, Rebollar et al. 1996a). The population at risk are men between 14 and 45 years of age who overnight in the forest (Andrade-Narváez et al. 1990). The transmission of the LCL is often related to the patient's occupation (Seidelin 1912, Beltran \& Bustamante 1942, Andrade-Narváez et al. 1992).

To know the timing of the transmission cycle in each focus of leishmaniasis is very important because highrisk season might be restricted. Thus, intervention measures such as prevention through medical education could be directed to the high-risk population. Moreover, epidemiological and ecological studies could be directed to that season and consequently the cost of research diminished.

The objective of the present study was to document the periodicity of the transmission of $L$. (L.) mexicana in the state of Campeche, Peninsula of Yucatan, Mexico. The multidisciplinary study included the incidence rate of patients with LCL during 1993-95, a two-years (March 1993 to March 1995) field research on small terrestrial rodents infected by $L$. (L.) mexicana (Chablé-Santos et al. 1995, Van Wynsberghe, unpublished data), and sand fly studies in the same site (Rebollar-Teller et al. 1996a, b) to obtain the rate and time of capture of infected rodents and sand flies between February 1993 and March 1995.

\section{MATERIALS AND METHODS}

Study area - The clinical study was performed in the whole state of Campeche $\left(17^{\circ} 48^{\prime} \mathrm{N}-20^{\circ} 47^{\prime} \mathrm{N}\right.$; $89^{\circ} 25^{\prime} \mathrm{W}-92^{\circ}$ $27^{\prime} \mathrm{W}$ ) while the rodents and sandflies collections site was located in a medium-sized subperennial forest located $8 \mathrm{~km}$ southeast of the village of La Libertad (18 34' N, $\left.90^{\circ} 31^{\prime} \mathrm{W}\right)$. The climate is subtropical with a relative humidity over $80 \%$, an unpredictable rain season (annual rainfall over $1401 \mathrm{~mm}$ ) mostly during the summer, and an 
average temperature of $27^{\circ} \pm 5^{\circ} \mathrm{C}$ (Flores \& Espejel Carvajal 1994).

Medical research - The clinical team responsible for epidemiological surveillance traveled monthly to the endemic area of LCL in the state of Campeche from January 1993 to December 1995. Patients from the Yucatan peninsula, Mexico, with a suggestive clinical picture of LCL, who sought treatment, were evaluated. This study was reviewed and approved by the Ethical Committee of the Universidad Autónoma de Yucatán, in agreement with international ethical guidelines for biomedical research involving human subjects (Ley General de Salud, Mexico). Written informed consent to participate was obtained from each patient. Eligibility for this study included a confirmed diagnosis of LCL based on visualization of the parasite by smear, biopsy, and/or isolation-culture (Garcia-Miss et al. 1990). Montenegro skin test was performed using a suspension of $1 \times 10^{6}$ promastigotes of $L$. (L.) mexicana (MHOM/MEX/83/UADYCV) in $0.5 \%$ phenol saline (Andrade-Narváez et al. 1990).

Mammalian research - The mammalian study was performed in medium-sized subperennial forest located $8 \mathrm{~km}$ southeast of the village of La Libertad, Campeche, from February 1993 to March 1995. The methods for the technique of capture-recapture as so for isolation-culture and Leishmania spp. identification have been described previously (Chablé-Santos et al. 1995).

Entomological research - Data selected to be analyzed in this study were taken from a two year study on vectors of LCL to document sylvatic transmission cycle in the state of Campeche, Mexico (Rebollar-Tellez et al. 1996a) and from a second study done to describe the abundance of antropophilic species of sand flies collected on human bait (Rebollar-Tellez et al. 1996b). Both studies were carried out in the same area where rodents were collected.

\section{RESULTS}

Medical research - Patients with a suggestive clinical picture of LCL were confirmed by the visualization of the parasite by smear, biopsy, and/or isolation-culture. A total of 111 cases were diagnosed. The monthly number of new cases presented a peak between February and March and very few ulcers appeared between June and November (Figure).

Mammalian research - In the two-years research, 184 rodents belonging to six species were studied in the laboratory. From April to October, no cutaneous signs of leishmanial infection were found (Figure), but during the next five months, i.e. from November to March, $L$. $(L$.) mexicana was isolated and identified by monoclonal antibodies from 22 rodents (Canto-Lara et al. 1999).

Entomological research - The two most probable vector of LCL in the Peninsula Lutzomyia o. olmeca and Lu. cruciata were the most abundant species captured deep in the forest from February 1993 to January 1994 ( $21.7 \%$ and $19.2 \%$ respectively). Although five anthropophilic species $(\mathrm{N}=888)$ were collected throughout the year, the 25 infected females were found only between November 1993 and February 1994. The rodentophilic $L$. o. olmeca (Shaw \& Lainson 1968) had the highest infection rate $(7.1 \%)$ and were the more abundant in October.
In the second study regarding abundance of antropophilic species of sand flies (Rebollar-Tellez et al. 1996b), the highest peak of Lu. cruciata was found in March with lesser peaks in December, January, and February (Figure).

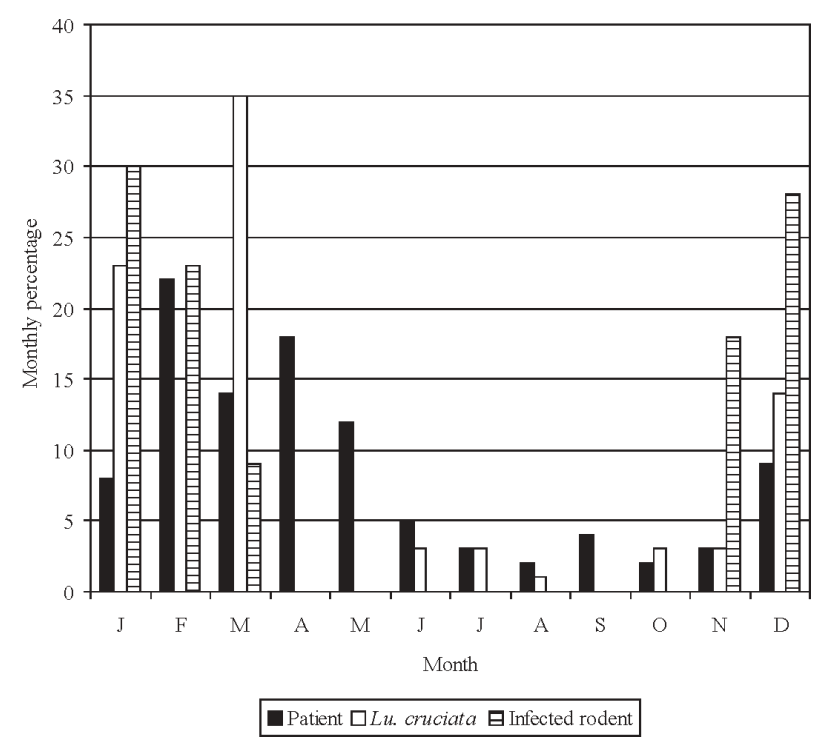

Monthly percentage of patients and rodents infected by Leishmania (Leishmania) mexicana, and relative abundance of Lutzomyia cruciata in a forest at $8 \mathrm{~km}$ from the village of La Libertad, Campeche, Mexico.

\section{DISCUSSION}

The present study is the first documented report in which each of the characteristics that ensure the transmission of the causing Leishmania spp. in a focus is comprehended.

It is well known that in an endemic area of LCL the geographical and temporal distributions and the habitats of reservoir, vector, and humans need to overlap (Bray 1987). To prove seasonally of transmission of a particular Leishmania spp., the cycle of transmission should not only occur during that specific season but the lack of potential transmission should be observed during the rest of the year. Based on results analyzed, it is concluded that $L$. (L.) mexicana in the endemic area of LCL in the state of Campeche, Yucatan Peninsula, Mexico, presents a seasonal transmission restricted to the months of November to March.

Although leishmaniasis can exist as a zoonosis for many years among wild animals and vector sand flies, when men enter the forest and establish their settlements, they are exposed to the bites of infected sand flies and become infected (Hashiguchi et al. 1985.) The future status of leishmaniasis in a newly-established village depends on the behavior of the inhabitants and the growth of the village, as pointed out by Herrer and Christensen (1976).

In the Yucatan Peninsula, the disease affected in the past mainly gum's collectors (most frequent economic activity) due to the fact that they entered frequently in the forest and overnight during months thus being in close contact with the phlebotomine vector especially at the 
dawn (Biagi \& de Biagi 1953). Beltran and Bustamante (1942) observed that LCL is an occupational disease of the gum collectors. Andrade-Narvaez et al. (1992), in an epidemiological study on LCL in the state of Campeche, identified the high-risk population as men ranging 15-45 years old, who enter the habitat with their animal of burden (Equus sp.) to cultivate (most common activity to date), collect gum, and hunt with their dogs. Their activities depended on the season. The Mayan agricultural methods which take place at a $10 \mathrm{~km}$ radius from the villages increase the contact of humans with both the mammalian reservoir and the anthropophilic vector. The fields are burned in April-May and planted immediately thereafter. The harvest is performed during the months of November-March. Gum collectors stayed for long periods of time (up to a month) deep into the forest where the largest gum-trees are still standing in the same period. Subsistence hunting takes place during the night mainly when the agricultural season is over (Ortega-Canto et al. 1996).

$P$. yucatanicus and $O$. phhyllotis have been incriminated as L. (L.) mexicana reservoirs based on: the geographic and temporal distributions and the habitats of reservoir, vector, and humans overlap: both of them are long-lived and the course of the infection is long and relatively nonpathogenic; and the most important, the species of the parasite present is the same in both the reservoir and in humans (Chablé-Santos et al. 1995, Van Wynsberghe et al. 2000).

Two sand flies are mainly involved in the transmission of the parasite, the anthropophilic Lu. cruciata and the rodentophilic Lu. olmeca. High abundance of the anthropophilic vector occurred between December and March (Rebollar-Téllez et al. 1996b) and the population of the rodentophilic sandfly peaked between October and January (Rebollar-Tellez et al. 1996a). When wild rodents were used to bait the vector $26 \mathrm{Lu}$. olmeca were captured during February 1994, representing $56.52 \%$ of the annual capture (Rebollar Téllez, unpublished data). Distribution of Lu. cruciata (Coquillet) in the Peninsula of Yucatan overlaps the distribution of localized cutaneous leishmaniasis (Biagi \& de Biagi 1953) and Lu. cruciata has been found as on of the most anthropophilic species of sand flies (Biagi et al. 1966, Cruz-Ruiz et al. 1994). Reproductive season of $\mathrm{Lu}$. cruciata occurred between December and March.

In summary, it appears that the forests of the Yucatan Peninsula have ideal ecological conditions for $L$. (L.) mexicana transmission, particularly in the winter season when high humidity, low temperature, would probably support increases in sand flies and also reservoir population. Although the number of human cases of LCL reported each year has a peak from March to July, if the incubation period is considered, there is a strong correlation between the abundance, rates, and timing of infection of both reservoirs and vectors. Therefore, the present study led us to document that the season of transmission of LCL caused by L. (L.) mexicana in the sylvatic region of the state of Campeche, occurs from November to March. More studies on quantitative epidemiology should be done to design control strategies focused to this season and high risk population affected.

\section{REFERENCES}

Andrade-Narváez FJ, Albertos-Alpuche NE, Canto-Lara SB, Vargas-González A, Valencia-Pacheco G, Palomo-Cetina A 1992. Risk factors associated with CL infection and disease in the State of Campeche, Yucatan Peninsula. In P Wijeyaratne, T Goodman (eds), Leishmaniasis Control Strategies. A Critical Evaluation of IDRC-supported Research, IDRC-MR 322e, Canada, p.193-205.

Andrade-Narvaez FJ, Simmonds-Diaz E, Rico-Aguilar S, Andrade-Narvaez M, Palomo-Cetina A, Canto-Lara SB, Garcia-Miss MR, Madera-Sevilla M, Albertos-Alpuche N 1990. Incidence of localized cutaneous leishmaniasis (chiclero's ulcer) in Mexico. Trans R Soc Trop Med Hyg 84: 219-220.

Beltran E, Bustamante ME 1942. Datos epidemiológicos acerca de la "úlcera de los chicleros" (leishmaniasis americana) en México. Rev Inst Salubridad y Enf Trop 3: 1-28.

Bettini S, Pozio E, Gradoni L 1980. Leishmaniasis in Tuscany (Italy): (II) Leishmania from wild Rodentia and Carnivora in a human and canine leishmaniasis focus. Trans $R$ Soc Trop Med Hyg 74: 77-83.

Biagi F, de Biagi AM 1953. Datos ecológicos de algunos flebótomos mexicanos (Diptera: Psychodidae). Anales Inst Biol (México) 24: 445-450.

Biagi F, de Biagi AM, Beltran F 1966. Actividad horaria de Phlebotomus antropofílicos en la Península de Yucatán. Rev Inv Salud Publica (México) 26: 73-77.

Bray RS 1987. Zoonoses and leishmaniasis. In DT Hart, Leishmaniasis: The Current Status and New Strategies for Control, Plenum Press, New York, p. 57-60.

Canto-Lara SB, Van Wynsberghe NR, Vargas-Gonzalez A, OjedaFarfán FF, Andrade-Narváez FJ 1999. Use of monoclonal antibodies for the identification of Leishmania spp. from humans and wild rodents in the state of Campeche, Mexico. Mem Inst Oswaldo Cruz 94: 305-309.

Chablé-Santos JB, Van Wynsberghe NR, Canto-Lara SB, Andrade- Narváez FJ 1995. Isolation of Leishmania (L.) mexicana from wild rodents and their possible role in the transmission of localized cutaneous leishmaniasis in the state of Campeche, Mexico. Am J Trop Med Hyg 53: 141145 .

Chaniotis BN, Correa MA, Tesh RB, Johnson KM 1971. Daily and seasonal man-biting activity of phlebotomine sandflies in Panama. J Med Entomol 8: 415-420.

Coronel V de, de Aroca MC, Hashiguchi Y 1987. Epidemiology 3: Parasitologically-proven retrospective cases diagnosed in INHMT, Chapter 7. In Y Hashiguchi, Studies on New World Leishmaniasis and its Transmission, with Particular Reference to Ecuador, Research Report Series No. 2, Kyowa Printing, Japan, p.140-159.

Cruz-Ruiz AL, Garcia-Rejon J, Manrique-Saide P, Perez-Mutul J 1994. Taxonomical identification of anthrophilic species in Quintana Roo, Peninsula of Yucatan, Mexico. Rev Biomédica 5: 127-131.

Flores JS, Espejel Carvajal I 1994. Tipos de Vegetación de la Península de Yucatán. Etnoflora Yucatanense 3, Universidad Autónoma de Yucatán Press, Yucatán.

García-Miss MR, Andrade-Narváez FJ, Esquivel-Viñas RE, Simmonds-Díaz EB, Canto-Lara SB, Cruz-Ruiz AL 1990. Sensitivity and specificity of ELISA for IgG antibodies to Leishmania mexicana mexicana. Trans $R$ Soc Trop Med Hyg. 84: 356-358.

Gentile B, Le Pont F, Pajot FX, Besnard R 1981. Dermal leishmaniasis in French Guiana: the sloth (Choloepus didactylus) as a reservoir host. Trans $R$ Soc Trop Med Hyg 75: 612-613. 
Gomez EAL, de Coronel VV, Hashiguchi Y 1990. Vector entomology. 2. Seasonal variation in the infection rates with Leishmania, and in the biting activity of the sand fly $L u$. ayacuchensis in an Andean leishmaniasis-endemic area of Ecuador, Chapter 4. In Y Hashiguchi, Studies on New World Leishmaniasis and its Transmission, with Particular Reference to Ecuador, Research Report Series No.2, Kyowa Printing, Japan, p. 49-60.

Hashiguchi Y, Gomez Landires EA, Vera de Coronel V, Mimori T, Kawabata M 1985. Natural infections with promastigotes in man-biting species of sand flies in leishmaniasis-endemic areas of Ecuador. Am J Trop Med Hyg 34: 440-446.

Herrer A, Christensen HA 1976. Epidemiological patterns of cutaneous leishmaniasis in Panama. I. Epidemics among small groups of settlers. Ann Trop Med Parasitol 70: 59-65.

Kerr SF, McHugh CP, Dronen Jr NO 1995. Leishmaniasis in Texas: prevalence and seasonal transmission of Leishmania mexicana in Neotoma micropus. Am J Trop Med Hyg 53: 73-77.

Lainson R 1988. Ecological interactions in the transmission of the leishmaniases. Phil Trans R Soc London 321: 389-404.

Lainson R, Strangways-Dixon J 1963. Reservoir hosts of Leishmania mexicana. The epidemiology of dermal leishmaniasis in British Honduras. Trans $R$ Soc Trop Med Hyg 57: 242-265.

Lainson R, Strangways-Dixon 1964. The epidemiology of dermal leishmaniasis in British Honduras. Part II. Reservoir-hosts of Leishmania mexicana among the forest rodents. Trans $R$ Soc Trop Med Hyg 58: 136-153.

Lindtjorn B 1984. Kala-azar in south-west Ethiopia: seasonal variation in disease occurrence. Trans $R$ Soc Trop Med Hyg 78: 790-791.

Ortega-Canto J, Hoil-Santos JJ, Lendechy Grajales A 1996. Leishmaniasis en milperos de Campeche (una aproximación médico-antropológica). Folleto de Investigación 5. Universidad Autónoma de Yucatán, Mérida, México.
Ready PD, Lainson R, Shaw JJ 1984. Habitat and seasonality of Psychodopygus wellcomei help incriminate it as a vector of Leishmania braziliensis in Amazônia and Northeast Brazil. Trans $R$ Soc Trop Med Hyg 78: 543-544.

Rebollar-Téllez EA, Ramírez-Fraire A, Andrade-Narváez FJ 1996a. A two-years study on vectors of cutaneous leishmaniasis. Evidence for sylvatic transmission cycle in the state of Campeche, Mexico. Mem Inst Oswaldo Cruz 91: 555-560.

Rebollar-Téllez EA, Reyes-Villanueva F, Fernandez-Salas I, Andrade FJ 1996b. Abundance and parity rate of Lutzomyia cruciata (Diptera: Psychodidae) in an endemic focus of localized cutaneous leishmaniasis in Southern Mexico. $J$ Med Entomol 33: 683-685.

Seidelin H 1912. Leishmaniasis and babesiasis in Yucatán. Ann Trop Med Parasitol 6: 295-299.

Shaw JJ, Lainson R 1968. Leishmaniasis in Brazil. II. Observations on enzootic rodent leishmaniasis in the lower Amazon region - The feeding habits of the vector, Lutzomia flaviscutellata in reference to man, rodents, and other mammals. Trans R Soc Trop Med Hyg 62: 396-405.

Strangways-Dixon J, Lainson R 1966. The epidemiology of dermal leishmaniasis in British Honduras. Part III. The transmission of Leishmania mexicana to man by Phlebotomus pessoanus, with observations on the development of the parasite in different species of Phlebotomus. Trans R Soc Trop Med Hyg 60: 192-207.

Travi BL, Montoya J, Solarte Y, Lozano L, Jaramillo C 1988. Leishmaniasis in Colombia. 1. Studies on the phlebotomine fauna associated with endemic foci in the Pacific coast region. Am J Trop Med Hyg 39: 261-266.

Van Wynsberhe NR, Canto-Lara SB, Damián-Centeno AG, ItzáOrtiz M, Andrade-Narváez FJ 2000. Retention of Leishmania (L.) mexicana in naturally infected rodents from the state of Campeche, Mexico. Mem Inst Oswaldo Cruz. 95: 595-600. 